\title{
Indoor Glutaraldehyde Levels in the Endoscope Disinfecting Room and Subjective Symptoms among Workers
}

\author{
Hiroshi KATAGIRI ${ }^{1 *}$, Toshio SUZUKI르, Yoshiharu AIZAWA ${ }^{3}$ and Takehiro KADOWAKI ${ }^{1}$ \\ ${ }^{1}$ Department of Public Health, Kitasato University School of Allied Health Sciences, 1-15-1 Kitasato, \\ Sagamihara 228-8555, Japan \\ ${ }^{2}$ Graduate School of Medical Sciences, Kitasato University, Japan \\ ${ }^{3}$ Department of Preventive Medicine and Public Health, Kitasato University School of Medicine, Japan
}

Received December 6, 2004 and accepted November 28, 2005

\begin{abstract}
We measured the environmental glutaraldehyde (GA) levels during the disinfection of endoscopes and also investigated the subjective symptoms of the workers engaged in that work. At 6 hospitals in the Tokyo and Kanagawa area, 8 rooms for endoscope washing and disinfecting the endoscopy equipment were surveyed. The geometric mean environmental GA levels in the 8 rooms were 1.3 to $19.6 \mathrm{ppb}$. The personal exposure levels at the time of replacing the antiseptic solution containing GA in two of the disinfecting rooms were 94.2 and $84.9 \mathrm{ppb}$. Subjective symptoms such as ophthalmic, nasal, respiratory, pharyngeal symptoms and nausea were more prevalent among workers than controls as evidenced from the questionnaire survey.
\end{abstract}

Key words: Glutaraldehyde, Endoscope, Disinfecting room, Working environment,

Subjective symptom

\section{Introduction}

Chemical substances influencing the health of workers are present not only in the industrial workplaces but also in hospitals. Various kinds of chemical substances in the form of liquids and gases are used particularly in sterilizing facilities. In 2001, ethylene oxide, used for sterilizing medical instruments, was specified as a specific chemical substance, and its use in the hospital has been controlled strictly by regulations.

Antiseptic solutions containing glutaraldehyde (GA) which has sterilizing and inactivation of viruses are used to sterilize endoscopes in the hospitals. GA is often used as a $2-5 \%$ solution, having a strong irritative odor since GA belongs to carbonyl compounds like formaldehyde and acetoaldehyde. Its reactivity with protein is so high that GA is used as a fixing solution in preparations for electron microscopy.

In Europe and the USA, GA has been used since the beginning of the 1960s; its irritation in the skin, mucous

*To whom correspondence should be addressed. membrane and airway has been pointed out. Patients complaining of headache, dermal symptoms and respiratory symptoms caused by GA have been reported ${ }^{1)}$.

In 1988, the British government revised the occupational exposure limit for the GA from $0.2 \mathrm{ppm}$ to $0.05 \mathrm{ppm}\left(0.2 \mathrm{mg} / \mathrm{m}^{3}\right.$ : 15 minutes mean value). In 1999 , the threshold limit value-ceiling (TLV-C) was revised from $0.2 \mathrm{ppm}$ to $0.05 \mathrm{ppm}$ in the U.S. as well ${ }^{2)}$. Europe and the USA restrict the use of GA more strictly than formaldehyde. In Japan, however, the danger of GA is still not generally recognized.

Therefore, we measured the environmental GA levels while disinfecting endoscopes and investigated the subjective symptoms of workers engaged in the disinfecting work.

\section{Subjects and Methods}

Outline of workplaces

The indoor GA measurements were conducted in 8 rooms for washing and disinfecting endoscopes at 6 hospitals (A-F) in the Tokyo and Kanagawa area in Japan. 
Automatic washers were used for the work in all the disinfection rooms. Prior to washing and disinfecting the endoscopes, they are first washed with tap water and then immersed in a vat of GA. Following the automatic washing, they are rinsed with tap water and dried.

The washing and disinfecting process in each workplace is shown in Table 1. The GA concentration was $3.5 \%$ except in hospital C, where $2.0 \%$ GA was used. The over-all washing/disinfecting took 45 to $55 \mathrm{~min}$, in which GA immersion was 15 to $20 \mathrm{~min}$. One to 3 automatic washers were equipped in each workplace, while GA immersion vats were used in only 2 workplaces. No ventilator was installed in any of the disinfection rooms.

\section{Sampling of $G A$}

Environmental air was collected by a diniturophenylhydrazine (DNPH) cartridge (Waters: Sep-Pak X Po-Sure) at the flow rate of $500 \mathrm{ml} / \mathrm{min}$ using a mini pump (SIBATA: MP- $\Sigma 30$ ) installed in the disinfecting room for 45 to $55 \mathrm{~min}$ from the start to the end of the automatic washer operation. The air was collected at 5 or 6 places in each disinfecting room as shown in Fig. 1.

\section{Personal exposure measurements}

The disinfecting solution containing GA is refilled after 2 to 4 wk use to maintain its disinfecting effects. The old antiseptic solution stored in an automatic washer is drained. After that, new antiseptic solution is poured in manually. It is a process of about $15 \mathrm{~min}$. Measurements were taken at the time of replacement in the disinfecting room of 2 hospitals, hospital C and D.

Collecting conditions and the DNPH cartridge were the same as for the environmental sampling. Sampling was conducted from the dorsal aspect or lateral aspect of workers engaged in the disinfecting work in the breathing zone while replacing antiseptic solution.

\section{GA determination}

Acetonitrile with the final volume of $3 \mathrm{ml}$ was injected into the DNPH cartridge and the recovered solution was used as the sample solution. Determinations of GA was performed by a high performance liquid chromatography (HPLC, GL Science: PU610, UV620). For HPLC analysis, column (Inertsil C8-3: $5 \mu \mathrm{m}, 250 \times 4.6 \mathrm{~mm}$ ) was used with an eluent of $\mathrm{CH} 3 \mathrm{CN} / \mathrm{H} 20-70 / 30$ at a flow rate of $0.7 \mathrm{ml} / \mathrm{min}$ at $40{ }^{\circ} \mathrm{C}$ and detected by ultra-violet

Table 1. Outline of washing and disinfecting work at six hospitals

\begin{tabular}{|c|c|c|c|c|c|}
\hline $\begin{array}{l}\text { Hospital And } \\
\text { room }\end{array}$ & $\begin{array}{l}\text { GA content of antiseptic } \\
\text { solution }(\%)\end{array}$ & $\begin{array}{l}\text { Total elapsed time washing } \\
\text { and disinfecting }\end{array}$ & $\begin{array}{l}\text { GA immersion } \\
\text { time }(\min )\end{array}$ & $\begin{array}{l}\text { Number of } \\
\text { Automatic washers }\end{array}$ & Immersion vat \\
\hline A A-1,A-2 & 3.5 & 45 & 15 & 3,1 & yes \\
\hline B B-1,B-2 & 3.5 & 55 & 20 & 1,1 & no \\
\hline $\mathrm{C} \mathrm{C}$ & 2.0 & 55 & 20 & 2 & no \\
\hline D D & 3.5 & 45 & 15 & 1 & no \\
\hline E E & 3.5 & 45 & 15 & 1 & no \\
\hline F F & 3.5 & 45 & 15 & 2 & yes \\
\hline
\end{tabular}
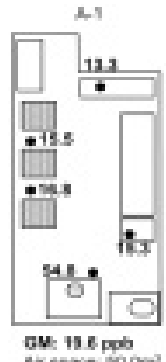

$\mathrm{c}$

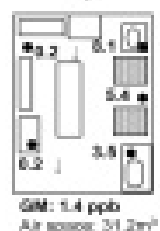

av: $24 \mathrm{ppb}$
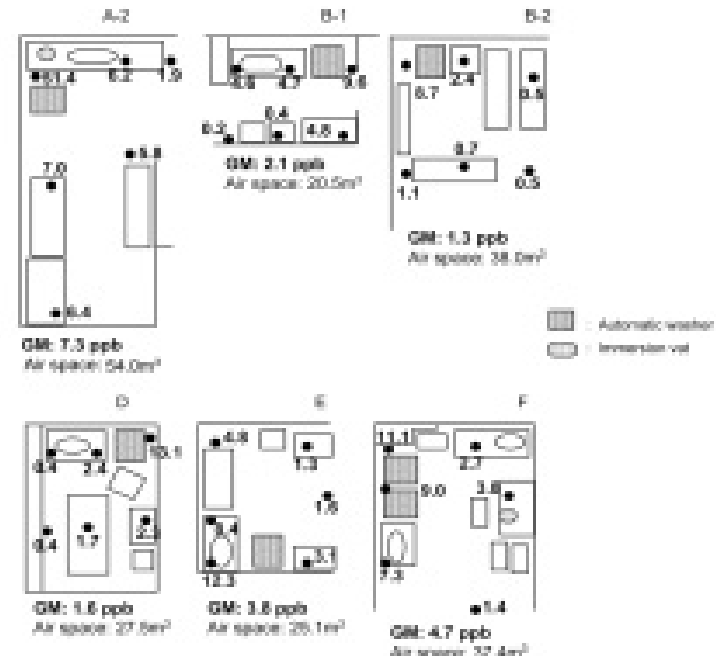

Fig. 1. Environmental GA level in each disinfecting room (ppb). 
(UV) $365 \mathrm{~nm}$.

\section{Subjective symptoms among workers}

A total of 31 women engaged in the endoscope washing and disinfecting work at 5 hospitals (A-E)were studied. Their mean age \pm standard deviation was $40.3 \pm$ 10.4. The controls were 101 women nurses and clerks with no GA exposure. Their mean age \pm standard deviation was $38.9 \pm 8.8$. The subjective symptoms by a selfadministered questionnaire in disinfecting workers were compared with the control group and statistically evaluated by the chi-square test.

\section{Results}

\section{Environmental GA levels in disinfecting room}

All disinfecting rooms were equipped with automatic washers as shown in Fig. 1. The environmental GA levels in each disinfection room are also shown. The highest GA level of $54.8 \mathrm{ppb}$ was found at the point near to the GA vat in room A-1, where 3 automatic washers and $\mathrm{GA}$ vat was placed. GA vats were present in Room A-1, A-2 and F, where an average of geometric means of GA appeared to be higher than the rooms without vats as shown in Table 2 with no statistical significance.

Personal exposure and enviornmental GA levels during refilling

Position of the refilling workers and places of environmental GA sampling during refilling of the antiseptic

Table 2. Mean levels of GA in room with or without vat

\begin{tabular}{ccc}
\hline Immersion Vat & Rooms & $\begin{array}{l}\text { Mean of geometric mean } \\
\text { GA level (ppb) }\end{array}$ \\
\hline Yes & A-1, A-2, F & $10.5 \pm 7.9$ \\
No & B-1, B-2, C, D, E & $2.0 \pm 1.0$ \\
\hline
\end{tabular}

solution are shown in Fig. 2.

The GA personal exposure level in the 15 min of refilling of antiseptic solution was $94.2 \mathrm{ppb}$ in room $\mathrm{C}$ and $84.9 \mathrm{ppb}$ for the workers in room $\mathrm{D}$, which exceeded $50 \mathrm{ppb}$ of threshold limit value-ceiling (TLV-C). The GA level in room $\mathrm{C}$ was as high as $60.7 \mathrm{ppb}$ at the nearest position of refilling work, followed by $58.0 \mathrm{ppb}, 57.6 \mathrm{ppb}$ at the adjacent places with a geometric mean level of $25.3 \mathrm{ppb}$. The GA level in room D was $30.7 \mathrm{ppb}$ at the nearest work position with a geometric mean level of $19.9 \mathrm{ppb}$.

\section{Subjective symptoms}

The prevalence of symptoms among disinfection workers and the control group as discovered by a questionnaire survey at 5 hospitals are shown in Table 3 .

At hospital A, 16 disinfection workers responded to questionnaires. The complaints were of nasal symptoms in $7(43.7 \%)$, respiratory symptoms in $7(43.7 \%)$, ophthalmic symptoms in $6(37.5 \%)$, nausea in $4(25.0 \%)$ and pharyngeal symptoms in $3(18.7 \%)$. At hospital B, 6 disinfection workers replied to the questionnaires and complained of ophthalmic symptoms and nasal symptoms. At hospitals $\mathrm{C}-\mathrm{E}$, the disinfection workers complained of ophthalmic, nasal, pharyngeal and respiratory symptoms.
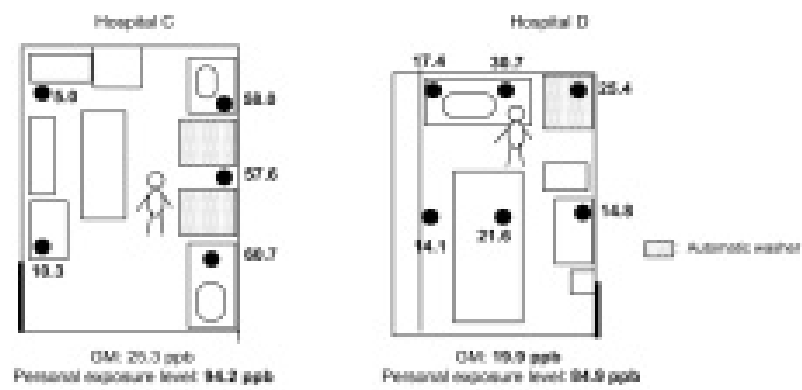

Fig. 2. Personal exposure level and environmental GA level at the time of replacing antiseptic solution.

Table 3. Subjective symptoms of workers engaging in disinfecting work

\begin{tabular}{cccccccc}
\hline Hospitals & $\begin{array}{l}\text { GA geometrical } \\
\text { Mean level (pp) }\end{array}$ & $\begin{array}{l}\text { Number of } \\
\text { subjects }\end{array}$ & \multicolumn{6}{c}{ Number of subjects complaining of nausea and irritation (\%) } \\
& & & Nausea & Eyes & Nose & Pharynx & Lower Airway \\
\hline A & $19.6,7.3 *$ & 16 & $4(25.0)$ & $6(37.5)$ & $7(43.7)$ & $3(18.7)$ & $7(43.7)$ \\
B & $12.1,1.3 *$ & 6 & $0(0.0)$ & $3(50.0)$ & $2(33.3)$ & $0(0.0)$ & $0(0.0)$ \\
C & 1.4 & 4 & $0(0.0)$ & $2(50.0)$ & $1(25.0)$ & $1(25.0)$ & $1(25.0)$ \\
D & 1.6 & 3 & $0(0.0)$ & $2(66.6)$ & $1(33.3)$ & $2(66.6)$ & $1(33.3)$ \\
E & 3.8 & 2 & $0(0.0)$ & $1(50.0)$ & $1(50.0)$ & $2(100)$ & $1(50.0)$ \\
\hline Total & & 31 & $4(12.9)$ & $14(45.2)$ & $12(38.7)$ & $8(25.8)$ & $10(32.2)$ \\
Control & & 101 & $2(2.0)$ & $14(13.8)$ & $5(5.0)$ & $5(5.0)$ & $9(8.9)$ \\
& & & $\mathrm{p}<0.05$ & $\mathrm{p}<0.01$ & $\mathrm{p}<0.01$ & $\mathrm{p}<0.01$ & $\mathrm{p}<0.01$ \\
\hline
\end{tabular}

*: Two disinfecting rooms. 
Table 4. Details of subjective symptoms

\begin{tabular}{llll}
\hline \multirow{2}{*}{ Number of subjects } & \multicolumn{1}{c}{ Workers } & Control \\
Nausea & Severe enough affecting job & 31 & 101 \\
& Others & $1(3.2 \%)$ & $0(0.0 \%)$ \\
& Pain & $8(25.8 \%) \mathrm{P}<0.01$ & $0(0.0 \%)$ \\
Eyes & Itching & $6(19.3 \%)$ & $8(7.9 \%)$ \\
& Lacrimation & $1(3.2 \%)$ & $6(5.9 \%)$ \\
& Conjunctival injection & $4(12.9 \%) \mathrm{P}<0.01$ & $0(0.0 \%)$ \\
\hline \multirow{2}{*}{ Nose } & Irritative odor & $11(35.4 \%) \mathrm{P}<0.01$ & $0(0.0 \%)$ \\
& Hyposmia & $0(0.0 \%)$ & $5(4.9 \%)$ \\
& Hyperosmia & $3(9.6 \%) \mathrm{P}<0.05$ & $0(0.0 \%)$ \\
\hline Pharynx & Irritation & $3(9.6 \%) \mathrm{P}<0.1$ & $1(0.9 \%)$ \\
& Pain & $4(12.9 \%)$ & $4(3.9 \%)$ \\
& Swelling & $2(6.4 \%) \mathrm{P}<0.1$ & $0(0.0 \%)$ \\
\hline Lower airway & Cough & $9(29.0 \%) \mathrm{P}<0.01$ & $5(4.9 \%)$ \\
& Sputum & $4(12.9 \%)$ & $4(3.9 \%)$ \\
& Asthma & $2(6.4 \%) \mathrm{P}<0.1$ & $0(0.0 \%)$ \\
& Difficulty in breathing & $1(3.2 \%)$ & $0(0.0 \%)$ \\
\hline
\end{tabular}

Comparing with subjective symptoms in the controls, a total of $31 \mathrm{GA}$ disinfection workers complained more frequently: ophthalmic symptoms in $14(45.2 \%$, p < 0.01), nasal symptoms in $12(38.7 \%, \mathrm{p}<0.01)$, respiratory symptoms in $10(32.3 \%, \mathrm{p}<0.01)$, pharyngeal symptoms in $8(25.8 \%, \mathrm{p}<0.01)$ and nausea in $4(12.9 \%, \mathrm{p}<0.05)$.

Table 4 shows the details of the symptoms. Nausea severe enough to affect the job was complained of by 3 workers $(9.6 \%, \mathrm{p}<0.05)$ of hospital A. Ophthalmic pain $(25.8 \%, \mathrm{p}<0.01)$ and conjunctival injection $(12.9 \%, \mathrm{p}<$ $0.01)$, irritative odor $(35.4 \%, \mathrm{p}<0.01)$ and hyperosmia (9.6\%, p < 0.05), swelling as pharyngeal symptoms, and asthmatic attacks and difficulty in breathing were complained of only among workers.

\section{Discussion}

Environmental measurements of GA in the 8 rooms for washing and sterilizing endoscopes by use of GA revealed geometric means of 1.3 to $19.6 \mathrm{ppb}$. The highest level of GA $19.6 \mathrm{ppb}$ observed in room A-1 was due to frequent use of automatic washers and leaving immersion vats in the room. The GA levels tended to be higher around automatic washers than other points in most rooms. Tendency of higher levels of GA was also detected in the vicinity of immersion vats compared with other points. These findings suggest that the automatic washers and immersion vats were the sources of GA. Therefore, efforts should be made to prevent the indoor contamination by opening and closing the lid rapidly when using the immersion vats and by doing the immersion work in a short time.

Automatic washers were used in all hospitals surveyed. However, manual washing and disinfecting work is done in some other hospitals. Pisaniello et al. ${ }^{3)}$ reported that the workplace environmental GA geometrical mean level during the manual washing of endoscopes is $8 \mathrm{ppb}$ in South Australia. They also reported that the mean GA exposure level in workers for manual washing was $32 \mathrm{ppb}$, and that 20 percent of the subjects had been exposed to more than $100 \mathrm{ppb}$.

The personal exposure level at the time of replacing work in the two rooms showed 94.2 and $84.9 \mathrm{ppb}$, which far exceeded TLV-C $50 \mathrm{ppb}$ of ACGIH. Even though the disinfectant-replacement work taking only $15 \mathrm{~min}$ and once every 2 to $4 \mathrm{wk}$, when pouring a new washing/antiseptic solution, the worker leaned forward and has his face close to the inlet port, so exposure to GA became a very high level. Latex gloves are the only protective measures at the time of this work. Since masks and goggles are not used, it may cause a high level exposure to the airway and eyes in a short time. Regarding protective gloves, butyl rubber gloves and nitrile rubber gloves are preferable since permeation of GA is found with latex gloves $^{4)}$.

Adequate measures to reduce the environmental GA levels such as a ventilation and wearing protective measures were not taken in the disinfecting rooms in this study. Presumably because of no legal control of GA use, the management of the work environment has not been 
adequately done. A guideline on management of disinfecting endoscopes in medical facilities was issued in February 2005.

As for the influence of GA on health, the toxic action consist of the corrosive and irritative actions. Vapor irritates the eyes and respiratory tract and it impairs tissues at high levels ${ }^{5,6)}$. Reportedly, the threshold of odors is $0.04 \mathrm{ppm}$ and the threshold to irritate the nose and oral mucosa is $0.3 \mathrm{ppm}$, however there is an individual difference. In persons with high sensitivity, the exposure to GA causes atrophy of the bronchus, resulting in symptoms of bronchial asthma. Asthma-like symptoms induced by inhalation of GA vapor may be due to hypersensitivity of the airway, but the mechanism is to be clarified. Contact with the GA solution was shown to cause allergic dermatitis ${ }^{7)}$.

Subjective symptoms revealed by the questionnaire survey in the GA workers were more prevalent than in controls for nausea, and the ophthalmic, nasal, pharyngeal and respiratory symptoms. Nausea was found only among the workers in a room with high levels of environmental GA which was high enough to prevent them from working. Since ophthalmic symptoms such as flickering with pain and conjunctival injection were complained of by the exposed workers but not by the controls, GA is suspected to have caused their symptoms. Among nasal symptoms, a feeling of irritation and hyperosmia were complained of only among the GA workers. As for pharyngeal symptoms and respiratory symptoms, some exposed workers complained of an irritative feeling of the pharynx and asthma-like attacks. These complaints are similar to the irritating effects caused by formaldehyde exposure. Wearing protective gear such as masks and goggles at work is needed.

Norback $^{8)}$ reported that the prevalence of symptoms of the nose and pharynx $(\mathrm{p}<0.05)$, headache $(\mathrm{p}<0.01)$ and nausea $(\mathrm{p}<0.01)$ among the endoscope washing and disinfecting workers in Swedish hospitals was significantly higher than in controls.

In Britain the use of GA has been banned for the use of endoscope disinfecting solutions since 2002, and ophthalaldehyde (OPA) has been recommended as a substitute. OPA has a stronger disinfecting effect against microorganisms than does GA. Moreover it has low volatility, low irritability and weaker odor. However, a substance with a strong disinfecting effect is likely to have a strong toxicity as well. When a substance has a low irritability, one is likely to feel it is not dangerous and not be as careful handling it. Among medical workers using an antiseptic solution containing OPA, they felt no irritation to the eyes and nose, but noticed blackening of the hands and clothes stained with the solution.

In addition to endoscopical use, GA is used as a disinfectant in dental treatments, fisheries, agriculture and also for indoor spaces. Because of direct exposure to large amounts of GA in endoscopic equipment disinfection, occupational health programs should be provided for workers handling GA in the workplace.

\section{Acknowledgements}

We wish to express our thanks to the participating hospitals for their cooperation with our investigation.

\section{References}

1) Leinster P, M Baum J, Baxter P J (1993) An assessment of exposure to glutaraldehyde in hospitals; typical exposure levels and recommended control measures. $\mathrm{Br}$ J Ind Med 50, 107-11.

2) ACGIH (2001) Glutaraldehyde. Threshold limit values for chemical substances and physical agents \& biological exposure indices. 34, ACGIH, Cincinnati.

3) Pisaniello DL, Gun R, Tkaczuk MN (1997) Glutaraldehyde exposure and symptoms among endoscopy nurses in South Australia. Appl Occup Environ Hyg 12, 171-7.

4) Jordan SL, Stowers MF, Trawick EG, Theis AB (1996) Glutaraldehyde permeation: choosing the proper glove. Am J Infect Control 24, 67-9.

5) Morandi M, Maberti S (2001) Glutaraldehyde. In: patty's Toxicology vol.5, 5th ed. eds. by Bingham E, Cohrssen B and Powell CH, 1031-6, John Wiley \& Sons, Inc., New York.

6) CCOHS: Available at http://www.ccohs.ca/oshanswers/ chemicals/chem_profiles/glutaraldehyde/working_glu.html (accessed Nov, 2003).

7) Ballantyne B, Berman B (1984) Dermal sensitizing potential of glutaraldehyde: a review and recent observations. J Toxicol Cut Occular Toxicol 3, 251-62.

8) Norback D (1988) Skin and respiratory symptoms from exposure to alkaline glutaraldehyde in medical services. Scand J Work Environ Health 14, 366-71. 